Supporting information for

\title{
Sustainable Dual Release of Antibiotic and Growth Factor from pH-Responsive Uniform Alginate Composite Microparticles to Enhance Wound Healing
}

Ming Shi, ${ }^{a, b}$ Hao Zhang, ${ }^{a, b}$ Ting Song, ${ }^{\text {a,b }}$ Xiaofang Liu, ${ }^{\text {a,b }}$ Yunfen Gao, ${ }^{a, b}$ Jianhua Zhou ${ }^{\mathrm{a}, \mathrm{b}, \mathrm{c}}$ and Yan $\mathrm{Li}^{\mathrm{a}, \mathrm{b}}{ }^{*}$

${ }^{\mathrm{a}}$ Guangdong Provincial Key Laboratory of Sensor Technology and Biomedical Instrument, School of Biomedical Engineering, Sun Yat-sen University, Guangzhou 510006, Guangdong, P.R. China

${ }^{\mathrm{b}}$ Guangdong Provincial Engineering and Technology Center of Advanced and Portable Medical Devices, Sun Yat-sen University, Guangzhou 510006, Guangdong, P.R. China ${ }^{\mathrm{c}}$ Division of Engineering in Medicine, Department of Medicine, Brigham and Women's Hospital, Harvard Medical School, Cambridge, MA 02139, USA

*Corresponding author: Yan Li, Telephone: +86-20-39332146, Fax: +86-20-39332146, Email: liyan99@mail.sysu.edu.cn 
Table S1. Summary of main fabrication parameters, characteristics and tests conducted for all samples

\begin{tabular}{|c|c|c|c|c|}
\hline $\begin{array}{l}\text { Sample } \\
\text { name }\end{array}$ & $\begin{array}{l}\text { Concentration of } \\
\mathrm{CaCO}_{3}(\mathrm{mg} / \mathrm{ml})\end{array}$ & $\begin{array}{l}\text { Entrapped } \\
\text { molecules }\end{array}$ & State & Tests conducted \\
\hline A-0-TB & 0 & $\begin{array}{l}\text { Trypan } \\
\text { blue }\end{array}$ & Hydrogel & Drug release \\
\hline A-5-TB & 5 & $\begin{array}{c}\text { Trypan } \\
\text { blue }\end{array}$ & Hydrogel & Drug release \\
\hline A-40-TB & 40 & $\begin{array}{c}\text { Trypan } \\
\text { blue }\end{array}$ & Hydrogel & Drug release \\
\hline AD-0-TB & 0 & $\begin{array}{c}\text { Trypan } \\
\text { blue }\end{array}$ & Lyophilized & Drug release \\
\hline AD-5-TB & 5 & $\begin{array}{l}\text { Trypan } \\
\text { blue }\end{array}$ & Lyophilized & Drug release \\
\hline AD-40-TB & 40 & $\begin{array}{l}\text { Trypan } \\
\text { blue }\end{array}$ & Lyophilized & Drug release \\
\hline A-40 & 40 & -- & Hydrogel & Cytotoxicity test \\
\hline AD-5 & 5 & -- & Lyophilized & Antibacterial test \\
\hline AD-5-R & 5 & rifamycin & Lyophilized & $\begin{array}{c}\text { Antibacterial and } \\
\text { cell proliferation } \\
\text { test }\end{array}$ \\
\hline AD-40 & 40 & -- & Lyophilized & Antibacterial test \\
\hline AD-40-F & 40 & $\mathrm{bFGF}$ & Lyophilized & $\begin{array}{c}\text { Cell proliferation } \\
\text { test }\end{array}$ \\
\hline CD-F-R & & $\begin{array}{l}\text { rifamycin } \\
\text { and bFGF }\end{array}$ & Lyophilized & $\begin{array}{l}\text { Antibacterial and } \\
\text { cell proliferation } \\
\text { test, animal test }\end{array}$ \\
\hline
\end{tabular}



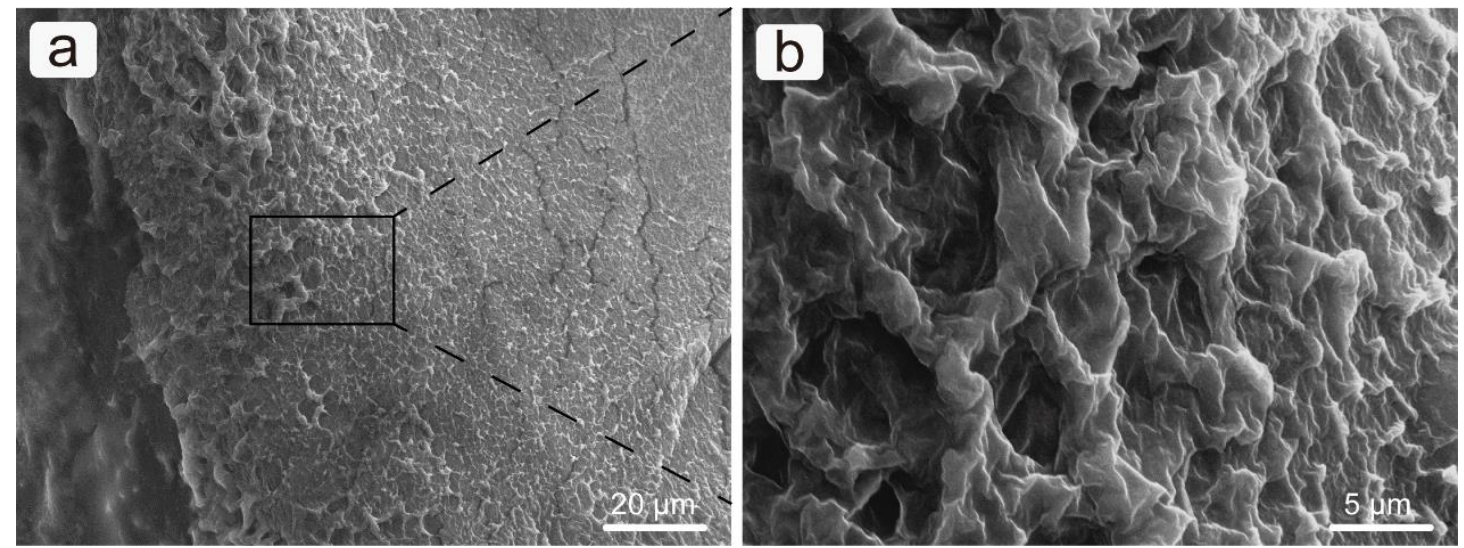

Fig. S1. SEM images of the surface of alginate microparticles prepared by adding surfactant Span 80 into the continuous phase DCM.

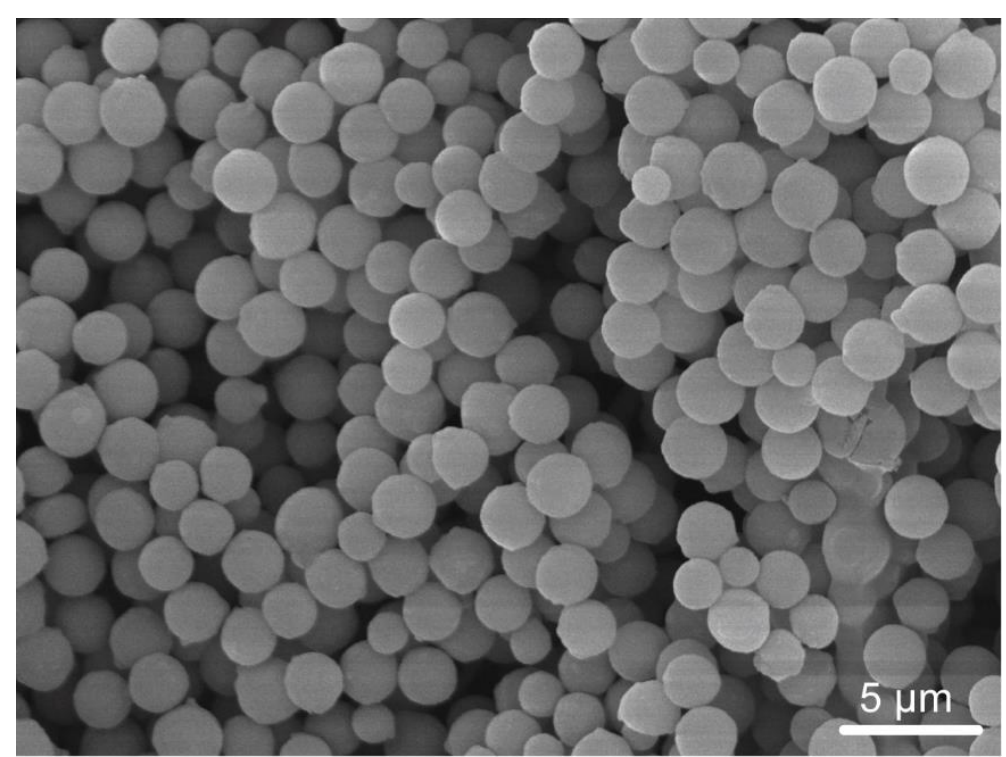

Fig. S2. SEM image of $\mathrm{CaCO}_{3}$ vaterite microparticles. 


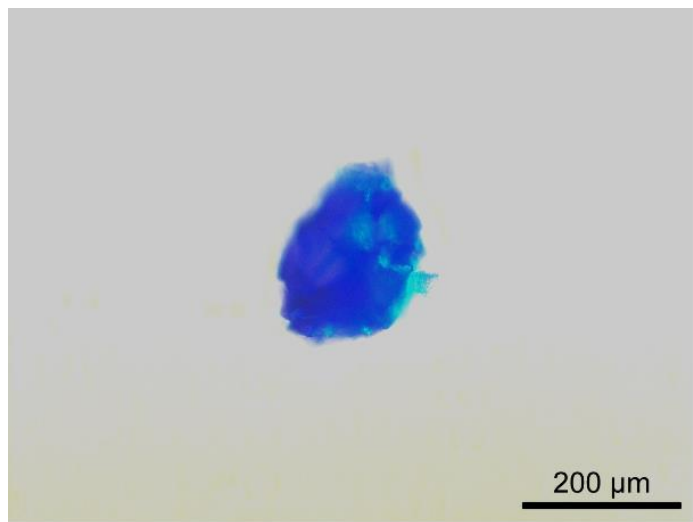

$0 \min$

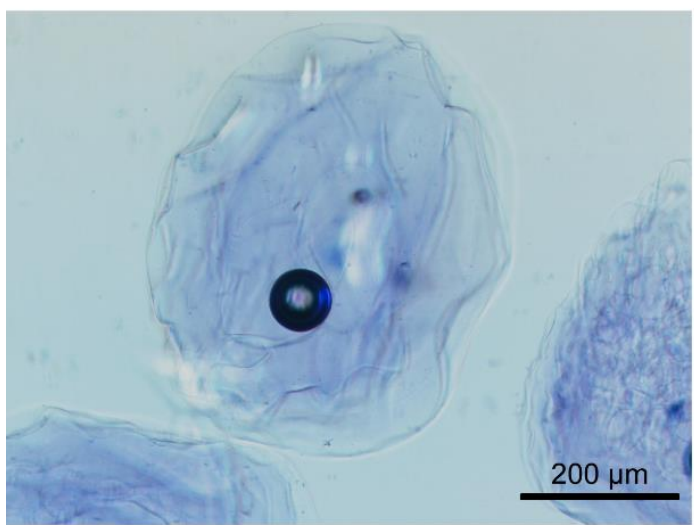

$15 \min$

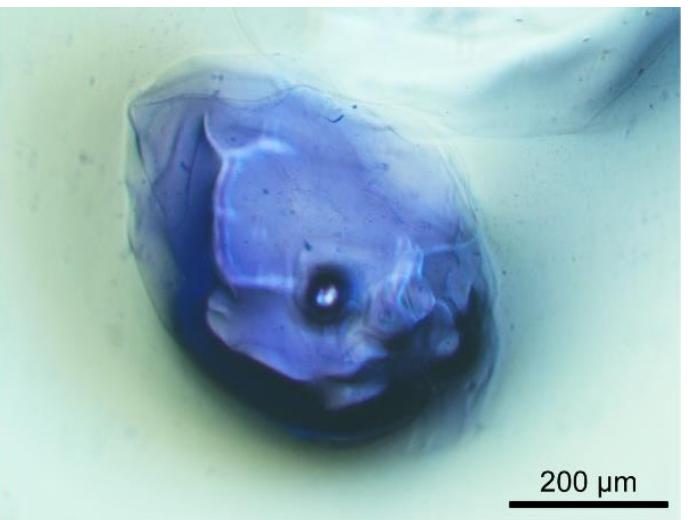

$10 \min$

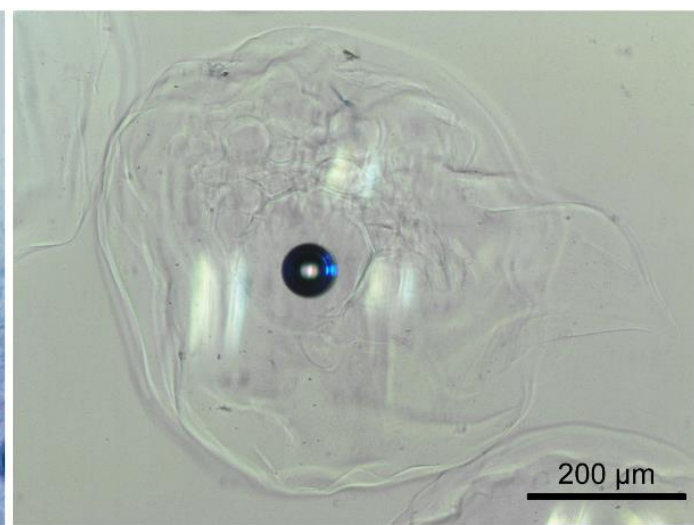

$30 \mathrm{~min}$

Fig. S3. (a) Light microscope images of AD-0-TB microparticles after incubation in PBS (pH 6.4, $37^{\circ} \mathrm{C}$ ) for various time. The image at 0 min was microparticles at lyophilization state. AD-0-TB microparticles were nearly dissolved after 30 min incubation.
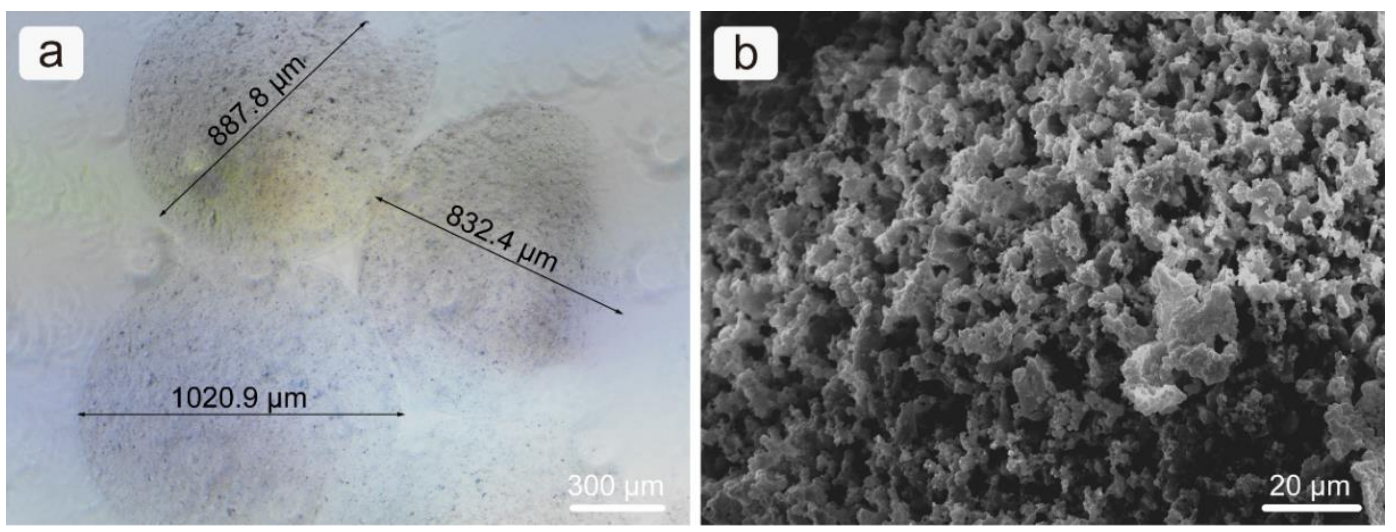

Fig. S4. (a) Light microscope image and (b) SEM image of A-40-TB microparticles after incubation for 6 days and cumulative release reaching $\sim 100 \%$. A-40-TB microparticles were significantly swollen as the diameter was nearly as twice as that for the as-prepared microparticles $(441 \mu \mathrm{m})$. The porous surface morphology was probably due to microparticles 
swollen and degradation.

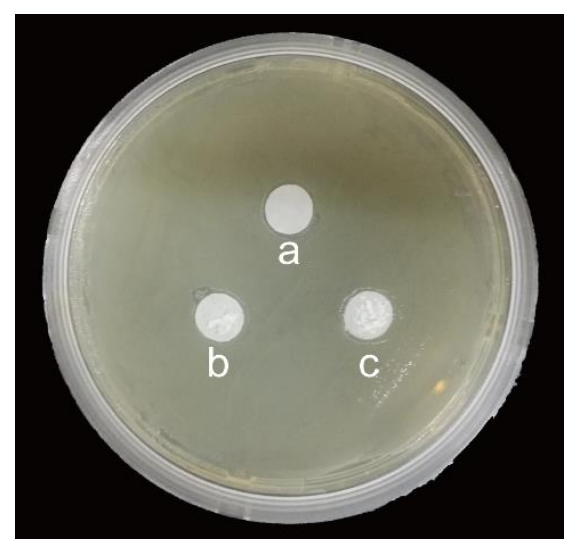

Fig. S5. Digital image of agar plate after incubating with control groups for $24 \mathrm{hr}$. (a) Filter paper, (b) filter paper with $A D-5$ and (c) filter with $A D-40$. Without rifamycin, there was no antibacterial effect was observed for these blank carriers.

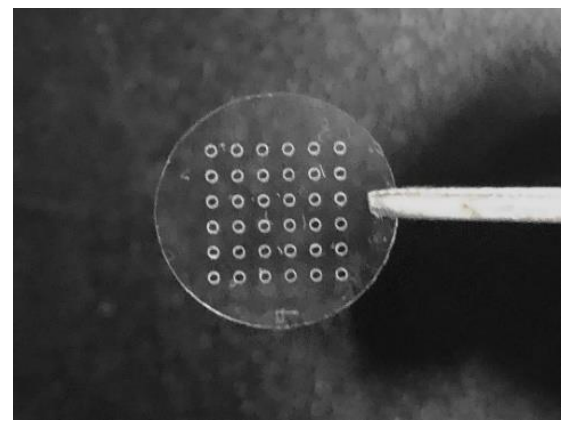

Fig. S6. Digital image of glass cover slip with $6 \times 6$ circular hole array which was fabricated with laser ablation. The diameter of each hole was $600 \mu \mathrm{m}$ and the center-to-center distance was $1.5 \mathrm{~mm}$ 